\title{
C-reactive protein is not related to ambulatory blood pressure or target organ damage in treated hypertensives
}

\author{
Michał Hoffmann', Katarzyna Polonis' ${ }^{1}$ Anna Szyndler ${ }^{1}$, Ewa Świerblewska', Katarzyna Kunicka', \\ Wiesława Kucharska', Robert Nowak', Jacek Wolf ${ }^{1}{ }^{1}$, Marzena Chrostowska', Krzysztof Narkiewicz ${ }^{1,2}$ \\ ${ }^{1}$ Department of Hypertension and Diabetology, Medical University of Gdansk, Gdansk, Poland \\ ${ }^{2}$ Department of Cardiovascular Diseases, International Clinical Research Centre, St. Anne's University Hospital in Brno (FNUSA), Brno, Czech Republic
}

\begin{abstract}
Summary
Background Publication of the JUPITER trial has renewed the interest in the use of CRP in cardiovascular risk prediction. The aim of the study was to assess the relationship between CRP, ambulatory blood pressure and target organ damage in a cohort of treated hypertensive males without overt cardiovascular disease.

Materials and methods The studied group consisted of 299 male hypertensive patients. Patients were stratified into low $(\leq 2 \mathrm{mg} / \mathrm{L})$, intermediate $(2-5 \mathrm{mg} / \mathrm{L})$, and high ( $>5 \mathrm{mg} / \mathrm{L}$ ) CRP groups. We measured ambulatory blood pressure, pulse wave velocity, left ventricular function and structure, carotid intima media thickness and ankle-brachial index. Results Twenty-six percent of the patients had CRP in the range of 2 to $5 \mathrm{mg} / \mathrm{L}$, and $12 \%$ had CRP levels exceeding $5 \mathrm{mg} / \mathrm{L}$. Ambulatory blood pressure and heart rate were not different across the three groups. Patients with high CRP had lower HDL cholesterol levels and higher plasma fibrinogen levels. Carotid femoral pulse wave velocity, carotid intima media thickness and ankle-brachial index were not different across the three groups. Echocardiographic data were also not related to the CRP level.

Conclusions

1. Elevated levels of CRP are frequently observed among treated patients with hypertension.

2. CRP elevation is associated with higher fibrinogen and glucose levels, and lower HDL cholesterol independently of obesity and smoking status.

3. Elevated CRP levels are not related to ambulatory blood pressure profile or target organ damage severity.

4. Our findings are consistent with the concept that CRP measurement is of limited value in cardiovascular assessment. key words: ambulatory blood pressure, arterial stiffness, C-reactive protein, hypertension, inflammation, left ventricular hypertrophy, pulse wave velocity, target organ damage
\end{abstract}

Arterial Hypertension 2015, vol. 19, no 1, pages: 45-49

DOI: $10.5603 / A H .2015 .0008$

\section{Background}

There is growing evidence supporting a role of inflammation and immunity in hypertension [1]. High-sensitivity C-reactive protein (CRP) has received the most attention among inflammatory bio- markers for its potential use in cardiovascular risk assessment [2]. Based on early studies linking high CRP to increased incidence of cardiovascular events in several clinical settings [3], its measurement in patients with arterial hypertension was recommended by the 2003 ESH/ESC guidelines [4]. More recent

Address for correspondence: Michał Hoffmann, MD, PhD

Department of Hypertension and Diabetology, Medical University of Gdansk

Debinki 7c, 80-952 Gdansk, Poland, tel: + 4858349 2527, fax: + 4858349 2601, e-mail: michalhoffmann@gumed.edu.pl

V M Copyright (C) 2015 Via Medica, ISSN 2449-6170

The study was supported by The Polish-Norwegian Research Fund (Novel Biomarkers of Cardiovascular Risk Evaluation in Northern Europe — CARE NORTH, PNRF-213-Al-1/07). Jacek Wolf and Krzysztof Narkiewicz are supported by European Regional Development Fund — Project FNUSA-ICRC (No. CZ.1.05/1.1.00/02.0123) and by the European Union — project ICRC-ERA-HumanBridge (No. 316345). 
studies [5] questioned added value of CRP in determining total cardiovascular risk. Consequently, the recommendation to measure CRP routinely in hypertensive patients was not sustained in the 2007 ESH/ESC guidelines [6].

Publication of the JUPITER trial [7] has renewed the interest in the use of CRP in cardiovascular risk prediction. The trial, which randomized $17,802 \mathrm{pa}-$ tients with $\mathrm{CRP}>2 \mathrm{mg} / \mathrm{L}$ to rosuvastatin $20 \mathrm{mg}$ versus placebo, was stopped early due to a robust $44 \%$ relative risk reduction in the primary endpoint. The risk reduction was directly related to baseline CRP levels [8]. Therefore, most of the recent CRP-related research efforts focused on its role as a predictor of clinical response to statin therapy. Much less is known about the importance of CRP in hypertension, especially in the setting of the antihypertensive therapy. Therefore, we assessed the relationship between CRP, ambulatory blood pressure and target organ damage in a cohort of treated hypertensive males without overt cardiovascular disease.

\section{Materials and methods}

\section{Subjects}

We studied 299 male hypertensive patients, aged 19 to 75 years, with essential hypertension, recruited from the outpatient clinic of the Department of Hypertension and Diabetology, Medical University of Gdansk. The patients were free of cardiovascular disease and diabetes. We have excluded patients with any acute disease potentially affecting the CRP level. The study was approved by the Institutional Human Subjects Review Committee. Informed written consent was obtained from all patients.

\section{Measurements}

Twenty-four hour ambulatory blood pressure and heart rate monitoring (ABPM) was performed with the Spacelabs 90207 recorder (Spacelabs Inc.). The recorders were programmed to obtain measurements every 20 minutes from $6 \mathrm{AM}$ to $10 \mathrm{PM}$, and every 30 minutes from 10 PM to 6 AM. Subjects were asked to continue their regular activities during the recordings, and to go to bed not later than $11 \mathrm{PM}$. The daytime period was defined as the interval from $8 \mathrm{AM}$ to $10 \mathrm{PM}$, and nighttime as the interval from midnight to $6 \mathrm{AM}$.

Carotid femoral pulse wave velocity (PWV) was measured with the Sphygmocor AtCor 232 device following the expert consensus document on the measurement of aortic stiffness in daily practice [9]. Carotid intima media thickness (IMT) was assessed using the ArtLab system (ArtLab, Esaote, Italy). Ankle-brachial index (ABI) was measured with the Minidop ES-100VX device (Hadeco Inc., Japan). Transthoracic echocardiographic recordings (Vivid $7 \mathrm{Pro}^{\mathrm{TM}} \mathrm{GE} ; 2.0-3.6 \mathrm{MHz}$ transducer) were obtained during quiet breathing after several minutes of rest. The following structural and functional heart properties were recorded according to American Society of Echocardiography [10] recommendations: left ventricle (LV) mass index, relative wall thickness (RWT), ejection fraction (LVEF), early (E) and atrial (A) trans-mitral flow velocities, and their ratio (E/A). High-sensitive plasma CRP in $\mathrm{mg} / \mathrm{L}$ was measured by the commercially available system (Roche Diagnostics Corp, Indianapolis, IN),

\section{Statistical analysis}

Results are expressed as means \pm SD. Patients were stratified into low $(\leq 2 \mathrm{mg} / \mathrm{L})$, intermediate $(2-5 \mathrm{mg} /$ $/ \mathrm{L})$, and high (>5 mg/L) CRP groups. Comparisons between the three groups were made by an analysis of variance (ANOVA) and analysis of the covariance (ANCOVA) followed by Scheffe's test for multiple comparisons. Fisher's exact test was used to determine differences in categorical variables between groups. All data were computed using Statistica 10 (StatSoft Inc). A P $<0.05$ was considered significant.

\section{Results}

Twenty-six percent of the patients had CRP in the range of 2 to $5 \mathrm{mg} / \mathrm{L}$, and $12 \%$ had CRP levels exceeding $5 \mathrm{mg} / \mathrm{L}$ (Figure 1 ).

Baseline characteristics of the patients grouped according to the CRP levels are provided in Table I. Patients with low CRP were less obese and were less likely to smoke. The three groups were comparable in terms of age and number of antihypertensive medications.

Ambulatory blood pressure and heart rate were not different across the three groups (Table II).

Table III presents laboratory findings of the patients subdivided according to the CRP levels. Patients with the low CRP levels had lower fasting plasma glucose than those with CRP $>2 \mathrm{mg} / \mathrm{L}$. Patients with high CRP had lower HDL cholesterol levels and higher plasma fibrinogen levels (Table III). These differences remained significant after adjustment for body mass index, waist-to-hip ratio and smoking status (Figures 2 and 3).

Carotid femoral pulse wave velocity, carotid intima media thickness and ankle-brachial index were not different across the three groups (Table IV). Echocardiographic data were also not related to the CRP level (Table V). 


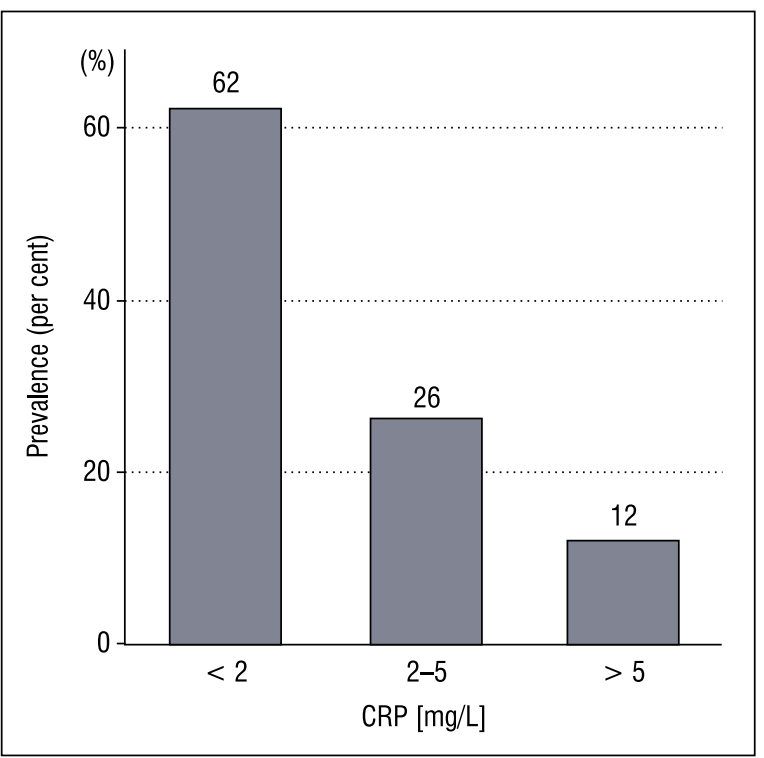

Figure 1. Distribution of patients grouped according to the CRP level

\section{Discussion}

The main findings in this study are first, that elevated levels of CRP are frequently observed among patients with hypertension despite antihypertensive treatment and reasonable blood pressure control. Second, CRP elevation is associated with lower HDL cholesterol and higher fibrinogen independently of obesity and smoking status. Third, elevated CRP levels are not related to ambulatory blood pressure profile or target organ damage severity. Thus, our data do not support the concept that CRP elevation may trigger cardiovascular events in treated patients by alteration of blood pressure diurnal profile or by potentiating hypertension-related cardiovascular damage.

More than one third of our patients had CRP levels above $2 \mathrm{mg} / \mathrm{L}$. High prevalence of elevated CRP is consistent with the results of the 2002 NATPOL PLUS survey (Nadciśnienie Tętnicze w Polsce Plus

Table I. Demographic data in patients grouped according to the CRP level

\begin{tabular}{|c|c|c|c|c|}
\hline & $\begin{array}{c}\text { CRP } \\
<2 \mathrm{mg} / \mathrm{L}\end{array}$ & $\begin{array}{c}\text { CRP } \\
2-5 \mathrm{mg} / \mathrm{L}\end{array}$ & $\begin{array}{c}\text { CRP } \\
>5 \mathrm{mg} / \mathrm{L}\end{array}$ & $\mathbf{P}$ \\
\hline Age (years) & $47.4 \pm 14.2$ & $49.6 \pm 13.4$ & $48.6 \pm 15.6$ & 0.52 \\
\hline $\mathrm{BMI}\left[\mathrm{kg} / \mathrm{m}^{2}\right]$ & $28.4 \pm 3.8$ & $30.0 \pm 4.6^{*}$ & $30.8 \pm 6.2^{*}$ & $<0.001$ \\
\hline Waist-to-hip ratio & $0.96 \pm 0.07$ & $1.00 \pm 0.06^{*}$ & $0.98 \pm 0.08^{*}$ & $<0.001$ \\
\hline Number of drugs & $2.5 \pm 1.5$ & $2.9 \pm 1.7$ & $2.8 \pm 1.2$ & 0.08 \\
\hline Smoking (\%) & 12.9 & 28.2 & 16.2 & 0.01 \\
\hline
\end{tabular}

Table II. Ambulatory blood pressure and heart rate in patients grouped according to the CRP level

\begin{tabular}{l|c|c|c|c}
\hline & \multicolumn{2}{c}{$\begin{array}{c}\text { CRP } \\
<2 \mathrm{mg} / \mathrm{L}\end{array}$} & $\begin{array}{c}\text { CRP } \\
\text { 2-5 mg/L }\end{array}$ & \multicolumn{1}{c}{$\begin{array}{c}\text { CRP } \\
\mathbf{5 m g} / \mathrm{L}\end{array}$} \\
\hline SBP daytime $[\mathrm{mmHg}]$ & $132.9 \pm 10.6$ & $133.9 \pm 11.3$ & $133.5 \pm 12.0$ & P \\
\hline SBP nighttime $[\mathrm{mmHg}]$ & $117.2 \pm 11.3$ & $120.2 \pm 12.2$ & $119.3 \pm 12.3$ & 0.76 \\
\hline DBP daytime $[\mathrm{mmHg}]$ & $81.5 \pm 7.9$ & $81.0 \pm 8.1$ & $81.5 \pm 10.8$ & 0.14 \\
\hline DBP nighttime $[\mathrm{mmHg}]$ & $68.8 \pm 8.4$ & $69.9 \pm 8.8$ & $70.6 \pm 11.6$ & 0.42 \\
\hline HR daytime $(\mathrm{bpm})$ & $74.3 \pm 9.2$ & $75.5 \pm 9.9$ & $75.7 \pm 12.6$ & 0.14 \\
\hline HR nighttime $(\mathrm{bpm})$ & $61.7 \pm 8.1$ & $64.1 \pm 8.6$ & $63.5 \pm 8.5$ & 0.08 \\
\hline
\end{tabular}

Table III. Unadjusted laboratory data in patients grouped according to the CRP level

\begin{tabular}{l|c|c|c|c}
\hline & \multicolumn{2}{c}{$\begin{array}{c}\text { CRP } \\
<2 \mathrm{mg} / \mathrm{L}\end{array}$} & $\begin{array}{c}\text { CRP } \\
\text { 2-5 mg/L }\end{array}$ & $\begin{array}{c}\text { CRP } \\
\mathbf{5 ~ m g / L}\end{array}$ \\
\hline Fasting glucose $[\mathrm{mg} / \mathrm{dL}]$ & $96.7 \pm 10.7$ & $102.4 \pm 12.7^{*}$ & $101.3 \pm 12.6^{*}$ & $<0.001$ \\
\hline LDL cholesterol $[\mathrm{mg} / \mathrm{dL}]$ & $123.6 \pm 34.6$ & $129.7 \pm 34.1$ & $121.3 \pm 41.0$ & 0.36 \\
\hline HDL cholesterol $[\mathrm{mg} / \mathrm{dL}]$ & $47.7 \pm 11.8$ & $44.5 \pm 11.9$ & $41.5 \pm 14.3^{*}$ & 0.007 \\
\hline Triglycerides $[\mathrm{mg} / \mathrm{dL}]$ & $133.8 \pm 77.3$ & $145.9 \pm 75.7$ & $140.0 \pm 60.2$ & 0.48 \\
\hline eGFR $\left[\mathrm{ml} / \mathrm{min} / 1.73 \mathrm{~m}^{2}\right]$ & $96.8 \pm 19.6$ & $98.0 \pm 16.0$ & $92.7 \pm 24.6$ & 0.38 \\
\hline Fibrinogen $[\mathrm{g} / \mathrm{L}]$ & $2.8 \pm 0.7$ & $3.2 \pm 1.1$ & $4.0 \pm 1.5^{* * *}$ & $<0.001$ \\
\hline
\end{tabular}




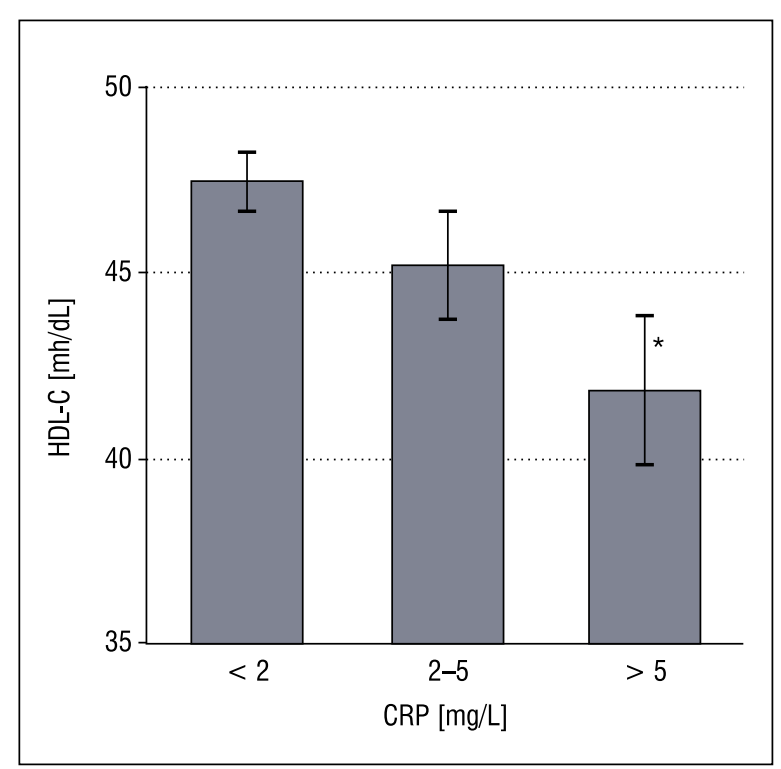

Figure 2. HDL cholesterol in patients grouped according to the CRP level after adjustment for body mass index, waist to hip ratio and smoking status. ${ }^{*} \mathrm{P}<0.05$ vs. patients with $\mathrm{CRP}<2 \mathrm{mg} / \mathrm{L}$ (analysis of covariance)

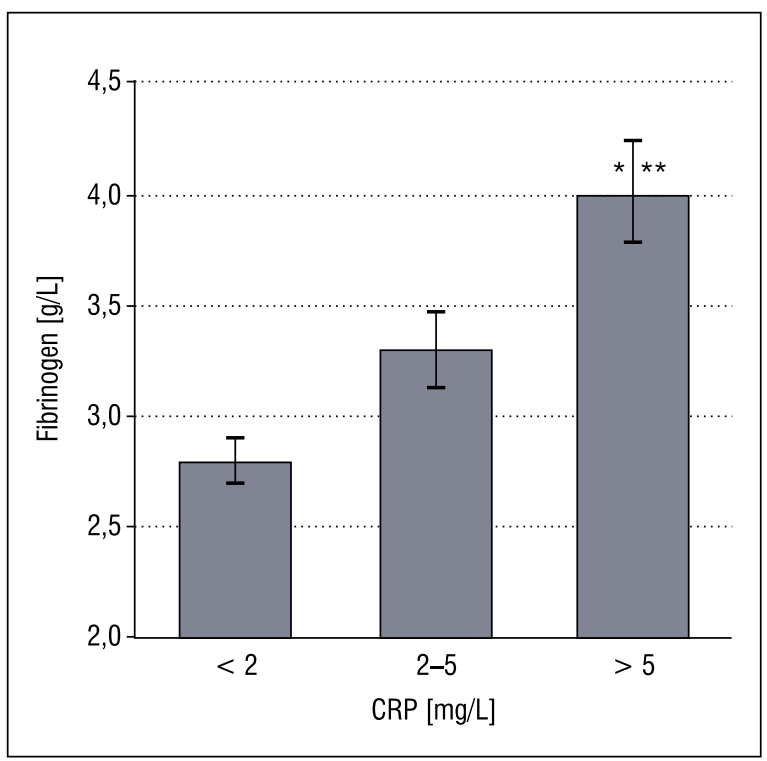

Figure 3. Plasma fibrinogen levels in patients grouped according to the CRP level after adjustment for body mass index, waist to hip ratio and smoking status. ${ }^{*} \mathrm{P}<0.001$ vs. patients with $\mathrm{CRP}<2 \mathrm{mg} / \mathrm{L} ;{ }^{*} \mathrm{P}<0.01$ vs. patients with CRP levels between 2 and $5 \mathrm{mg} / \mathrm{L}$ (analysis of covariance)

Table IV. Ankle-brachial index (ABI), carotid-femoral pulse wave velocity (PWV) and carotid intima-media thickness (IMT) in patients grouped according to the CRP level

\begin{tabular}{|c|c|c|c|c|}
\hline & $\begin{array}{c}\text { CRP } \\
<2 \mathrm{mg} / \mathrm{L}\end{array}$ & $\begin{array}{c}\text { CRP } \\
2-5 \mathrm{mg} / \mathrm{L}\end{array}$ & $\begin{array}{c}\text { CRP } \\
>5 \mathrm{mg} / \mathrm{L}\end{array}$ & $\mathbf{P}$ \\
\hline$A B I$ & $1.14 \pm 0.11$ & $1.14 \pm 0.14$ & $1.11 \pm 0.12$ & 0.52 \\
\hline $\mathrm{PWV}$ [m/s] & $9.7 \pm 2.0$ & $10.0 \pm 2.0$ & $9.8 \pm 1.7$ & 0.51 \\
\hline IMT [mm] & $0.65 \pm 0.16$ & $0.66 \pm 0.13$ & $0.68 \pm 0.17$ & 0.44 \\
\hline
\end{tabular}

Table V. Echocardiographic data in patients grouped according to the CRP level

\begin{tabular}{|c|c|c|c|c|}
\hline & $\begin{array}{c}\text { CRP } \\
<2 \mathrm{mg} / \mathrm{L}\end{array}$ & $\begin{array}{c}\text { CRP } \\
2-5 \mathrm{mg} / \mathrm{L}\end{array}$ & $\begin{array}{c}\text { CRP } \\
>5 \mathrm{mg} / \mathrm{L}\end{array}$ & $\mathbf{P}$ \\
\hline LVMI $\left[\mathrm{g} / \mathrm{m}^{2}\right]$ & $115.4 \pm 26.2$ & $107.8 \pm 23.5$ & $118.0 \pm 32.6$ & 0.06 \\
\hline RWT & $0.50 \pm 0.07$ & $0.50 \pm 0.08$ & $0.48 \pm 0.07$ & 0.20 \\
\hline $\mathrm{EF}(\%)$ & $69.5 \pm 8.1$ & $70.5 \pm 7.6$ & $67.3 \pm 7.6$ & 0.18 \\
\hline $\mathrm{E}[\mathrm{m} / \mathrm{s}]$ & $73.2 \pm 15.6$ & $73.5 \pm 16.8$ & $75.6 \pm 15.2$ & 0.76 \\
\hline $\mathrm{A}[\mathrm{m} / \mathrm{s}]$ & $68.4 \pm 13.8$ & $70.4 \pm 14.3$ & $70.2 \pm 19.0$ & 0.60 \\
\hline$E / A$ & $1.11 \pm 0.32$ & $1.09 \pm 0.35$ & $1.15 \pm 0.36$ & 0.75 \\
\hline
\end{tabular}

Zaburzenia Lipidowe i Cukrzyca - Arterial Hypertension in Poland Plus Lipid Disorders and Diabetes) reporting increased level of CRP (defined as > $1 \mathrm{mg} / \mathrm{L}$ ) in $52 \%$ of adult males and in $62 \%$ of male hypertensives in Poland [11]. In the present study, we have used the CRP cut-off point of $2 \mathrm{mg} / \mathrm{L}$ similarly to that used in the JUPITER trial [7]. Furthermore, such classification is consistent with the ARIC (Atherosclerosis Risk in Communities) study, in which patients with CRP $>2 \mathrm{mg} / \mathrm{L}$ had a higher risk of $\mathrm{CV}$ events than individuals with low CRP level [12].

We were able to confirm results of earlier studies showing that elevated CRP is independently linked to higher plasma fibrinogen and glucose levels, and to lower HDL cholesterol levels, which can trigger both atherosclerosis and acute cardiovascular events [2].

The results of the previous studies linking CRP to arterial stiffness [13-17] and carotid intima-media thickness [18-22] are not consistent. Discrepancies 
in the results of earlier studies might be explained by a number of factors including presence of co-morbidities and previous treatment, age of the studied subjects and methodological aspects. In our study, we were not able to demonstrate any relationship between CRP and vascular damage in treated hypertensive patients. Our findings are in agreement with the results of another Polish study performed in untreated patients [17]. Similarly to our study, Sypniewska et al. [17] were not able to document and link between CRP and left ventricular mass index. The novel finding of our study is lack of the relationship between CRP and left ventricular function.

Our study was limited to males. The relationship between CRP, ambulatory blood pressure and target organ damage may be different in females. We did not assess endothelial function, which could provide further insights into relationship between inflammation and cardiovascular damage. In mitigation, we have carefully applied all methods of cardiovascular phenotyping suggested by the 2013 ESH/ESC guidelines [23]. Furthermore, we measured ambulatory blood pressure in all patients excluding whitecoat hypertension.

\section{None.}

\section{Conflict of Interest}

\section{Conclusions}

1. Elevated levels of CRP are frequently observed among treated patients with hypertension.

2. CRP elevation is associated with higher fibrinogen and glucose levels, and lower HDL cholesterol independently of obesity and smoking status.

3. Elevated CRP levels are not related to ambulatory blood pressure profile or target organ damage severity.

4. Our findings are consistent with the concept that CRP measurement is of limited value in cardiovascular assessment.

\section{References}

1. Harrison D.G., Guzik T.J., Lob H.E. et al. Inflammation, immunity, and hypertension. Hypertension 2011; 57: 132-140.

2. Yousuf O., Mohanty B.D., Martin S.S. et al. High-sensitivity C-reactive protein and cardiovascular disease: a resolute belief or an elusive link? J. Am. Coll. Cardiol. 2013; 62: 397-408.

3. Ridker P.M. High-sensitivity C-reactive protein: potential adjunct for global risk assessment in the primary prevention of cardiovascular disease. Circulation 2001; 103: 1813-1818.

4. 2003 European Society of Hypertension-European Society of Cardiology guidelines for the management of arterial hypertension. Guidelines Committee. J. Hypertens. 2003; 21: 1011-1053.
5. Wang T.J., Gona P., Larson M.G. et al. Multiple biomarkers for the prediction of first major cardiovascular events and death. N. Engl. J. Med. 2006; 355: 2631-2639.

6. Mancia G., De Backer G., Dominiczak A. et al. 2007 Guidelines for the Management of Arterial Hypertension: The Task Force for the Management of Arterial Hypertension of the European Society of Hypertension (ESH) and of the European Society of Cardiology (ESC). J. Hypertens. 2007; 25: 1105-1187.

7. Ridker P.M., Danielson E., Fonseca F.A. et al. Rosuvastatin to prevent vascular events in men and women with elevated $\mathrm{C}$-reactive protein. N. Engl. J. Med. 2008; 359: 2195-2207.

8. Ridker P.M., MacFadyen J., Libby P., Glynn R.J. Relation of baseline high-sensitivity C-reactive protein level to cardiovascular outcomes with rosuvastatin in the Justification for Use of Statins in Prevention: an Intervention Trial Evaluating Rosuvastatin (JUPITER). Am. J. Cardiol. 2010; 106: 204-209.

9. Van Bortel L.M., Laurent S., Boutouyrie P. et al. Expert consensus document on the measurement of aortic stiffness in daily practice using carotid-femoral pulse wave velocity. J. Hypertens. 2012; 30: 445-448.

10. Nagueh S.F., Appleton C.P., Gillebert T.C. et al. Recommendations for the evaluation of left ventricular diastolic function by echocardiography. J. Am. Soc. Echocardiogr. 2009; 22: 107-133.

11. Zdrojewski T., Chwojnicki K., Bandosz P., Konarski R., Wyrzykowski B. Distribution of C-reactive protein and its relation to arterial hypertension in a country representing a high-risk region for cardiovascular diseases. Blood Press. 2006; 15: 20-26.

12. Yang E.Y., Nambi V., Tang Z. et al. Clinical implications of JUPITER (Justification for the Use of Statins in Prevention: an Intervention Trial Evaluating Rosuvastatin) in a U.S. population: insights from the ARIC (Atherosclerosis Risk in Communities) study. J. Am. Coll. Cardiol. 2009; 54: 2388-2395.

13. Kampus P., Kals J., Ristimae T., Fischer K., Zilmer M., Teesalu R. High-sensitivity C-reactive protein affects central haemodynamics and augmentation index in apparently healthy persons. J. Hypertens. 2004; 22: 1133-1139.

14. Schumacher W., Cockcroft J., Timpson N.J. et al. Association between C-reactive protein genotype, circulating levels, and aortic pulse wave velocity. Hypertension 2009; 53: 150-157.

15. McEniery C.M., Spratt M., Munnery M. et al. An analysis of prospective risk factors for aortic stiffness in men: 20-year follow-up from the Caerphilly prospective study. Hypertension 2010; 56: 36-43.

16. Gomez-Marcos M.A., Recio-Rodríguez J.I., Patino-Alonso M.C. et al. Relationships between high-sensitive C-reactive protein and markers of arterial stiffness in hypertensive patients. Differences by sex. BMC Cardiovasc. Disord. 2012; 12: 37.

17. Sypniewska G., Pollak J., Strozecki P. et al. 25-hydroxyvitamin D, biomarkers of endothelial dysfunction and subclinical organ damage in adults with hypertension. Am. J. Hypertens. 2014; 27: 114-121.

18. Makita S., Nakamura M., Hiramori K. The association of C-reactive protein levels with carotid intima-media complex thickness and plaque formation in the general population. Stroke 2005; 36: 2138-2142.

19. Takahashi W., Ohnuki T., Honma K., Kawada S., Takagi S. The significance of multiple risk factors for early carotid atherosclerosis in Japanese subjects. Intern. Med. 2007; 46: 1679-1684.

20. Okazaki S., Furukado S., Abe Y. et al. Association of inflammatory markers and carotid intima-media thickness with the risk of cardiovascular events in high-risk patients. Cerebrovasc. Dis. 2010; 30: $180-187$.

21. Amer M.S., Elawam A.E., Khater M.S., Omar O.H., Mabrouk R.A., Taha H.M. Association of high-sensitivity C-reactive protein with carotid artery intima-media thickness in hypertensive older adults. J. Am. Soc. Hypertens. 2011; 5: 395-400.

22. Choi H., Cho D.H., Shin H.H., Park J.B. Association of high sensitivity C-reactive protein with coronary heart disease prediction, but not with carotid atherosclerosis, in patients with hypertension. Circ. J. 2004; 68: 297-303.

23. Mancia G., Fagard R., Narkiewicz K. et al. The Task Force for the management of arterial hypertension of the European Society of Hypertension (ESH) and of the European Society of Cardiology (ESC). 2013 ESH/ESC Guidelines for the management of arterial hypertension. J. Hypertens. 2013; 31: 1281-1357. 